\title{
English Language Teachers in Diaspora: A Heideggerian Phenomenology
}

\author{
Gino G. Sumalinog \\ Cebu Normal University, Cebu City, Philippines \\ https://orcid.org/0000-0002-5967-4769
}

\begin{abstract}
Working abroad has been a job that many Filipino teachers embarked on due to the benefits it offers. This paper explores the lived experiences of the ten (10) Filipino ESL and EFL teachers working in Mozambique, Cambodia, Spain, Saudi Arabia, Cambodia, Japan, Laos, Singapore, Vietnam, and Thailand. These teachers have been in service for three (3) years and more. The study employed a qualitative phenomenological research design. It used Heideggerian's Interpretative Phenomenological Analysis (IPA) with illustrated steps. The researcher uses a semi-structured interview to identify the lived experiences these participants have come across. The virtual data are gathered by means of Skype and Facebook Messenger. After an intensive analysis of the data, five themes emerged: (a) the driving force of the participants; (b) boons of the sojourn; (c) life learning encounters with students, and (d) scaffolds for the success of the sojourn. The findings reveal that the sojourn of the teachers in a foreign land had produced positive results and meaningful life experiences that had developed them economically, personally, and professionally. For future directions, researchers may delve deeply into the informants' cultural encounters with their students and colleagues.
\end{abstract}

Keywords: Interpretative Phenomenological Analysis; lived experiences; ESL/EFL teachers; Filipino teachers abroad

\section{Introduction}

As the world moves towards raising the bar of excellence in education, it also seeks to find more competent and world-class teachers. As a result, schools in other foreign countries hire teachers regardless of race and ethnicity giving more priority to competence, character, and abilities to deal with students in a complex and diverse classroom. Thus, teachers became noble professionals due to the bulk of tasks that they do and their dedication to imparting knowledge, skills, and morals to students. However, a country's educational system does not always fully and justly compensates for the efforts and accomplishments. In other parts of the world, the teaching profession gets valued more than any other job. 
For example, New Zealand hires kinder and music teachers for Montessori schools. However, the country only recruits skilled applicants that can pass the International English Language Test System (IELTS) as well as the assessment administered by the New Zealand Teachers Council. Even though English is the official language in the United States, it still hires competent teachers since the country's teachers are not enough to educate the increasing population of American students.

The country mainly recruits Math, Science, Music, and English teachers in preschools and secondary schools. Though these countries differ in their hiring guidelines, they follow almost similar qualification criteria. They require applicants to be college graduates possessing an Education degree (pre-school secondary or college). For applicants aspiring to go to Singapore, New Zealand, and the US, teachers must pass and obtain an IELTS average of 7.0. Adding to this, the teaching experience they are required to have ranges from 2-5 years (Alase, 2017). At present, Filipino teachers have been spread worldwide in search of teaching opportunities despite the downsides they get. The Philippine Statistics Authority in 2019, released an article stating that the Overseas Filipino Workers (OFWs), including teachers, who are currently working abroad reached up 2.3 million from April to September 2018. 96.2 percent of the Overseas Filipino Workers (OFWs) have existing legal contracts, while 3.8 percent do not have contracts.

These numbers are increasing each year and the possibility of seeing higher data of teachers going out of the country is also predictable. The reasons for these professionals are varied. The good thing is that the government is continuously protecting its people from illegal recruiters and bogus agencies from indirectly preying over the interested teachers. This move results in a favourable experience for the sojourn teachers. In this regard, Altun (2015) mentions that teachers are subject to benefit abroad better from their country of origin, for they get to experience and develop teaching techniques. Upon their return, they tend to become more imaginative and manipulative in their classes. Due to their journey outside their comfort zone, they encounter varied curricula, get in contact with teachers originating from other countries, and eventually get professionally developed. In the long run, these teachers can develop materials to enliven their classroom and make each teaching-learning time productive.

Therefore, the challenges and gains of Filipino teachers working abroad are worth-studying. There are still young teachers who are aspiring to work as teachers abroad. In this vein, it is fitting to examine the lived experiences of Filipino English teachers. Their experiences can provide an eye-opener to others who wish to work abroad. This study could contribute to the personal and professional experiences of ESL and EFL teachers. These experienced teachers can then influence the administrators and curriculum implementers to enhance the present educational system. The result of this study can be the basis for the improvement of the country's internationalization. It can also raise the percentage of successful ESL and EFL teachers. 


\section{Related Literature}

Teaching in other countries is an adventure that teachers remembered for a lifetime. Teachers get the chance to enhance their skills through the predeparture resources, training, and support from the government and their sponsoring agencies (Explore Asia, 2020). According to Toraman, Ozdemir and Orakci (2020), teachers become more motivated to go abroad to prove themselves worthy of being chosen among the many applicants. They feel more confident that they have what it takes to be foreign teachers abroad. They also become curious to learn about other country's culture and experience living abroad. Serin (2017) stated that teaching abroad includes a package of benefits such as having international experience, learning about cultural practices, and understanding people from diverse cultures.

On the same note, Johnson (2013) expressed that teaching abroad becomes attractive to many due to the offered incentives and benefits that the schools abroad could afford. Teachers preferred to teach overseas because of the high salary (Serbes, 2017). For Ulla (2019), teachers went abroad to teach and learn at the same time to support their families, learn how to handle EFL learners, acquire new methodologies and strategies. In the same line of thought, Walters (2020) mentioned that most teachers who went abroad could save money, learn a new language, experience personal growth, gain perspectives of life, and help others land the same job. Teachers could explore other places and take advantage of a global work experience that enhanced personal and professional teaching skills (Council on International Exchange [CIEE], 2020). Pachina (2020) said that teachers also got the chance to brush elbows with business people from different professions and interact with them in person.

ESL and EFL teaching abroad is a transformational experience. Teachers meet new people from diverse backgrounds, try new foods and delicacies, and visit fascinating places near their locations (Online English Teaching Jobs [OETJ], 2020). Teachers learned about managing the classroom, developing instructional materials, motivating students effectively, involving technology in their content and pedagogy, and making the classroom inclusive and conducive for both the students and the teacher (Celik, 2017). Teaching in a new setting gives so much pleasure and happiness that money could not equate, despite the drawbacks. The experience fulfilled the desire to try something new, but the dream is to make the best out of the experience (Zayed, 2018). Accordingly, a life-long fulfilment could come into the reality that changed their lives forever.

In the same manner, teachers also understand the rich and complex cultural differences of their students. Specifically, these teachers become adaptive, confident, determined, tolerant, understanding, and respectful of other people's views. They could encourage their students to be gain consider and global perspectives (Kong, 2020). With experiences outside one's culture, teachers dramatically become empowered both in their personal and professional characteristics (Markoulias, 2020). Looking at the different practices that teachers performed in the foreign school they were employed, they enjoy enhancing their teaching techniques and professional growth. They acquired a new and broader 
view of the educational practices which they may use in their own country (Kong, 2020). Moreover, Ellwood (2015) added that teachers handling international students gain experience interacting with other cultures and understand the complexity of the host country's practices and customs.

However, Tseng \& Newtown (as cited in Alghamdi \& Otte, 2016) report that working abroad is associated with language difficulties, discrimination, and homesickness. Gul \& Gokce (2020) added that teachers also meet professional problems such as grasping a new curriculum, familiarizing learners' interests, and creating a harmonious relationship with co-workers and administrators. As far as non-native English teachers are concerned, they were sometimes doubted by their students and administrators just because they are non-native speakers of English. Administrators and students sometimes believe that native English teachers are better teachers (Tosuncuoglu, 2017). Non-native English teachers carry heavy pressure against their native English counterparts. They attempt to sound native, work more than expected, and stand against discrimination (Bolgoa, 2019). In reality, both native and non-native English teachers struggled to contextualize their teaching strategies with their foreign learners. In this sense and according to Ulla (2018), both teachers experience hindrances to students' learning, including lack of exposure to the English language, a nonestablished English curriculum, insufficient teachers' training, and lack of interest in learning English. For Altun (2015), teachers who work abroad also encounter varied curricula that are different from the ones they have followed.

With regard to these issues, teachers should remember that the focus in education is quality learning and experience. In this concern, instructors should be considerate in dealing with learners' cultural differences (Medved, Franco, Gao \& Yang, 2013). Similarly, since teachers love being treated well by their students, they must try to call their students by their names no matter how difficult they are and learn to approach students' opinions about common issues (Kisch, 2013). Besides, Lee (as cited in Medved et al., 2013) suggests teachers should reduce their talking speed, so students would have the opportunity to understand them and engage in a friendly conversation with them that could result in mutual respect. Bassett (2018) adds that while teachers are outside their comfort zones, they are well encouraged to establish relationships with residents, the people working in a school, and others they may meet.

Consequently, the experience could bolster teachers' curriculum vitae (CV) and further their educational careers back in the Philippines. The years they spent teaching could make them weigh whether the job was suitable for them or not. They also got the chance to grab insights into the life of foreign educators. They learned new moves applicable in any classroom scenario that they might have if they would still teach in the Philippines upon return (Bryan, 2020), and their skills could go a long way even upon their return. 


\section{Methodology}

This section displays the research design used in this study, the employed research instruments, and the informants involved. It also specifies the inclusion and exclusion criteria used in selecting the informants.

\subsection{Research Design}

This paper explores the lived experiences of the informants using the qualitative phenomenological research design. It notably uses the Heideggerian Interpretative Phenomenological Analysis (IPA) which mostly suites the objectives of this research paper. It provides exact steps and a stance in understanding and interpreting the lived experiences of the involved informants. When used as an approach, the IPA mainly shows an informantoriented nature (Alase, 2017).

\subsection{Research Environment}

The study is conducted virtually with the informants' involvement from the different schools abroad where they worked as English as Second Language (ESL) or English as Foreign Language (EFL) teachers. These schools are limited to international schools within Asia, and these schools offer English language courses, implement English language instruction, and accept Filipino English teachers. These schools are from Mozambique, Cambodia, Spain, Saudi Arabia, Cambodia, Japan, Laos, Singapore, Vietnam, and Thailand. These countries offer English language curricula differently from the ones our country is currently practicing.

\subsection{Research Informants}

Ten informants are Filipino English teachers involved in this study. This number fell within Laverty's (2003) criteria when he stated that there should be five to twenty-five individuals who have experienced the phenomenon. These ten informants narrate their lived experiences as English as a Second Language (ESL) teachers. Generally, the informants are bachelor's degree graduates in any of the schools in the Philippines. They are currently teaching English as Second Language (ESL) or as English as Foreign Language (EFL) in any primary school abroad.

\subsection{Inclusion Criteria}

The informants are needed to be in service for more than three years to provide the intended data. The informants should be ESL or EFL teachers handling English classes in any primary schools abroad. They should be at least bachelor's degree holders and graduates of any teacher education degrees in the Philippines. Furthermore, the informants should make it through the criterionbased purposive sampling procedure.

\subsection{Research Instruments}

A semi-interview is used in this study wherein the interview schedule goes through a validation process involving three language researchers and experts. The purpose from this research tool is to explore and examine Filipino teachers' lived experiences as English teachers abroad. The answers are collected through Skype and Facebook messenger. 


\section{Data Analysis}

The Interpretative Phenomenological Analysis (IPA) data analysis method comprised of five steps as enumerated below:

\subsection{Looking for Themes in Each Case}

In this step, the transcript was read and re-read several times to gain intimacy and familiarity with the transcripts. Besides, the transcript was a margin where anything significant, engaging and striking statements laid.

\subsection{Looking for Connections}

In this stage, the emerging themes are listed and clustered on the paper's right side. The transcript is suggested to be returned in hope to check the accuracy of the information.

\subsection{A Table of Themes}

This stage displayed all the themes that are clustered, labelled, and ordered coherently according to connections. This process needs careful attention to avoid biases.

\subsection{A Master List of Themes for the Group}

As the analysis progressed following the Interpretative Phenomenological Analysis (IPA), the final list of themes emerged. In this stage, the researcher needs to avoid biases too.

\subsection{Write Up}

This step was concerned with writing reports for publication or submission for a degree using the master list of themes. The narration of facts became the main task of the researcher.

\section{Results and Discussion}

After a careful and extensive analysis of the transcripts, six themes related to the lived experiences emerged, and are as follows: (a) the driving force of the informants; (b) boon of the sojourn; (c) life learning encounters with students, and (d) scaffold for the success of the sojourn.

\section{Theme 1: Driving force of the Informants}

Altun (2015) mentioned that teachers who work abroad significantly benefit from their country of origin in terms of money and other perks. Teachers go abroad to teach and learn at the same time to support their families, learn how to handle EFL learners, acquire new methodologies and strategies (Ulla, 2019). In the informants of this study, they go abroad primarily for financial reasons, for they have families to support, needs to meet, investments to realize, business to establish, and siblings to send to school. Secondly, they also desire to emerge in a new culture, experience a new environment, get international teaching experience, and a chance to travel abroad. However, the other informants shared about their sojourn, yet with emphasis on economic reasons. Despite the vacant teaching positions in the Philippines' public and private schools, they still insisted on going abroad. To experience a new culture and live in a new 
environment have still been their desires, but they highlighted their motives to earn to help their families and put off investments. They have listed some desires such as: owning a house, pay their loans, and save for their families.

Looking at the informants' responses, they have common reasons that were centered not only towards meeting their wants and desires, but also meeting the needs of immediate family members. On the same note, Johnson (2013) expresses the same idea that teaching abroad becomes attractive to many due to the offered incentives and benefits the schools abroad could afford. Put simply, teachers prefer to teach overseas because of monetary reasons (Serbes, 2017). Toraman, Ozdemir and Orakci (2020) added that teachers also become curious to learn about other countries' cultures, experience living abroad, and the chance to earn better than the salary they are getting from where they previously worked. Besides earning, they also significantly hope to experience a new environment and culture in the flesh. Stepping into foreign soil attract them to leave their countries. They believed that sojourning into another country to work could be worthy and life-fulfilling.

\section{Theme 2: Boons of the Sojourn}

Teaching abroad could lead to many opportunities for teachers to enhance their teaching techniques and uplift their lives. As they face a new type of learners, they encounter new curricula in the host country. As they teach, they try new methodologies and experiment with effective teaching means. At the same time, they also develop their knowledge of the content. They get to experience with their senses and observe how teachers from other countries teach. Teachers learn about managing the classroom, developing instructional materials, motivating students effectively, involving technology in their content and pedagogy, and making the classroom inclusive and conducive for both the students and the teacher (Celik, 2017). In the context of the informants' experience, they all admit that the journey gave them more benefits than the negative impact it brought to them. They cite that they have grown personally, professionally, and economically.

To begin with, they got to experience a salary that was twice up to six times higher than how much the Philippine government paid its teachers (Altun, 2015). Based on their answers, from the beginning, the informants mainly went abroad to earn, to honestly get higher pay. They earned more because they also had part-time jobs for 2-4 hours as English educators and tutors every night after their classes. These proved that these teachers are exhausting all the means that they could resort to earn extra besides their salaries. The informants happily shared that their economic status has improved. There was a significant difference between their past and current earnings, yet they refused to mention where their money went. On the other hand, some of them highlighted that they had bought a small lot, paid a loan, and were able to send their siblings to school. However, two of them claimed that their income from their work and part-time jobs have gone a long way. They explained that they had supported the studies of their siblings as well as the needs of their families. One of the 
research informants mentioned that investing and supporting the needs of her family and siblings are also met to a great extent.

Though it was never ideal for comparing how immense the salary difference between the Philippines and abroad teachers, their comfort from being close to their family members could not match with money alone. However, the money earned in a foreign land could also make a significant change in the teachers' aspirations and dreams in life. Concerning the respondents' personal growth, they had expanded their understanding regarding students' behaviour and learning styles in class. Nonetheless, three of them highlighted that they exhausted their creativity before going there and fit them into the target context. Some others have developed the sense of understanding in which they became patient when students found the lessons difficult to understand. Their ability to react to negative classroom situations has improved more. One of them stated that it was genuinely possible to tolerate cultural differences and learn variations.

The findings displayed the positive characteristics they gained from experience. Expectedly, they already had all these attributes before their employment abroad. Accordingly, these teachers had only practiced them more. They had only gotten the chance to test them in different contexts and in new situations. In the same manner, teachers also understand the rich and complex cultural differences of their students. Specifically, these teachers become adaptive, confident, determined, tolerant, understanding, and respectful of other people's views. They all insisted that they had grown personally, making them confident, open-minded, and flexible.

With the different practices the teachers performed in the foreign school they were employed in, teachers enjoyed enhancing their teaching techniques and professional growth. They acquired a new and broader view of the educational practices which they may use in their own country (Kong, 2020). They became exposed to varied teaching approaches and class delivery styles (Expat Quotes, 2020). In this study, the teachers explicitly replied that they had gained professional teaching skills and new strategies to help them handle their current students. They proudly imparted that all the learning experiences they had in the classroom have contributed to the "better teachers" versions of themselves. For example, two of them stressed that they had learned to manage the learning behaviour of students from another culture.

Based on the informants' responses, they had become adaptive and equipped with the needed skills in teaching. They learned varied strategies to address the learning style of the learners despite cultural differences. The professional growth they gained was worth keeping, for these could go a long way. The teachers, as long as they continue teaching, could directly use these in their profession.

\section{Theme 3: Life Learning Encounters with the Students}

Though education focuses on quality learning and experience, professors should be considerate in dealing with the learners' cultural differences (Medved et al., 
2013). The teachers asserted that their employees had some memorable events which they would remember all their lives even after their employment years. These events were either positive or negative. The negative experiences resulted in good results, those that awaken them about cultural differences, and those that made them the better teachers that they are now. Teachers seriously played their roles as second parents to the students. The students would soon pay tribute to the kindness of the teachers by showing respect and love. For example, two of the research informants emphasized that the school and its administrators were consistent in inculcating respect to the students' minds at all times. They were overwhelmed by how their students respected them. It gave them pleasure despite the homesickness they felt. They felt relieved that their fear that students might disrespect them and throw them some papers like what they often saw in the Western part of the world might happen to them. On the other hand, three others also experienced the utmost respect their students who never failed to manifest their love to them too.

The students' gestures were essential to the psychological aspect of the teachers, for their teaching became light and easy since the learners they were with were easy to manage. Among the informants, only one went further and explained that the interesting difference between Japanese and Philippine schools was the heavier emphasis on morals and ethics education in Japan. They respect teachers above everyone else in school. Despite the majority of the informants' heartwarming experiences, one of them gave a comment that was completely contradicting the other teachers' experience. It has been claimed that students in Spain were less respectful than the Filipino students. It is also quite surprising to be called by the students by the teacher's name without "Ma'am" "Teacher". Understandably, calling the teacher's first name in Spain was normal to them, but not following the Filipinos' practices; that's why it appeared awkward and off. However, the same participant admitted that she knew the culture well; she was just uncomfortable listening to the students not calling him, "Ma'am."

Looking at the teachers' experiences regarding their encounters with the students, it was clear that respect could come from the school's teaching sometimes; what students perceived to be normal might still appear undesirable to teachers due to cultural differences.

\section{Theme 4: Scaffolds for the Success of the Sojourn}

Teaching abroad was an uncertain journey, for the paths ahead might end in fulfilment, if not in unfortunate disgrace. The informants insisted that before a teacher decided to work abroad, they all agreed that internal and external support should be present so that working away from home could be endured.

To start with, teachers insisted that teaching outside the country could be through ESL teaching experience, strong will, and motivation. They believed that exposure to students from other cultures such as the Koreans, Japanese, Chinese and other nationalities in ESL institutions, English language schools, and English tutorial centres in the Philippines could be of great help. In this light, the informants highlighted that ESL teaching had been their best guide and their advantage over the challenges. On the other hand, one of them 
expressed how thankful she was for having an ESL experience. Some others firmly believed that motivation is the main factor that teachers needed in working abroad. Yet, for one participant, experience and motivation could fuel aspiring teachers who wished to work abroad.

However, among them, only one wanted to have training and seminars. In contrast, one of the basic requirements when working abroad was pre-departure training and orientation. Therefore, getting trained was not an issue for others. In short terms, the informants were on the same boat regarding the support that teachers could give themselves to be fully ready when working abroad. They all adhered to the importance of motivation and job experience to promote successful foreign teaching employment.

Regarding the so-called External Support, the informants shared that the government could contribute to their successes. They wished the TEFL certificates are free of charge for Filipino teachers heading abroad. The teachers hoped that language training for the countries they were heading is government-sponsored. They even wanted that English teachers' internship would include handling international students to prepare them for the ample opportunities that the ESL field had in store. These heroes all acknowledged the importance of having a TEFL certificate, though not required, for it could be an advantage over the other applicants. Based on their observations, most of the promoted employees in their workplaces were TEFL holders. To have one, they wished that government may help them acquire one for free.

Besides the TEFL certificate, the informants had seen another vital need that could be addressed by the government through the Commission on Higher Education (CHED). Three of them claimed for internship to be part of the curriculum. One of them added that future English teachers need exposure to support the theories introduced in classes. Indeed, there was a need for exposure to foreign language learners that most of the informants believed so. The emerged themes only suggested that life is an unpredictable cycle of daily experiences where its details can be tried and lived. The experiences then become the guiding principles and blueprints for the other dreamers who wish to go abroad.

\section{Conclusion}

Based on the findings, the informants went abroad primarily for financial reasons. They have families to support, needs to meet, investments to realize, business to establish, and siblings to send to school. Secondly, they also desired to emerge in a new culture, experience a new environment, get international teaching experience, and a chance to travel abroad. Moreover, teaching abroad could lead to many opportunities to enhance their teaching techniques and better their lives. As they faced a new type of learners, they encountered new curricula in the host country. As they teach, they tried new methodologies and experiment with effective teaching means. It has been concluded that before a teacher decided to work abroad, they all agreed that internal and external supports should be present so that working away from home could be endured. 
For future directions, researchers could seize the opportunities to delve deeply into the informants' cultural encounters with their students and colleagues.

\section{Implications}

Exploring the lived experiences of English teachers working abroad could open a series of insights. This output could positively influence not only experimenting theories, practices, and policies, but also the following:

\subsection{To the Teachers}

This study could pose awareness to all the teachers, no matter what level they are handling on going abroad. Knowing this information beforehand could lead the teachers to think a million times whether to gamble their comfort zones against an uncertain journey.

\subsection{To the Students}

The students who are part of the reading public could get a gist of what it will be like to be in their teachers' place. With it, students could become more understanding of the complexity of the teaching profession. They could start planning about their future, including the greener future that going abroad could give them.

\subsection{To the Field of English Language Teaching}

The field of English Language Teaching (ELT) has been continuously updating, and hence this study could contribute to the expected change through its novelty.

\subsection{To the Researchers}

As researchers dig for new trends, this paper's result, which exposed them to international work experience, could lead them to a more narrowed inquiry in terms of the ESL/EFL teachers' lived experiences. They could seize the opportunities to delve deeply into the informants' cultural encounters with their students and colleagues.

\section{References}

Alase, A. (2017). The interpretative phenomenological analysis (IPA): A guide to a good qualitative research approach. International Journal of Education $\mathcal{E}$ Literacy Studies, 5(2), 12-13. doi:10.7575/aiac.ijels.v.5n.2p.9

Alghamdi, H., \& Otte, S. (2016). The challenges and benefits of study abroad. International Journal of Humanities and Social Science, 6(5), 17. Retrieved from http://www.ijhssnet.com/journals/Vol_6_No_5_May_2016/2.pdf

Altun, M. (2015). The role of working abroad as a teacher in professional development. International Journal of Academic Research in Progressive Education and Development., 4(4), 102-103. doi:10.6007/IJARPED/v4-i4/1937

Bassett, R. (2018). Intercultural adjustment for teachers abroad (Master's thesis, St. Cloud State University, New Mexico, USA). Retrieved from https:/ / repository.stcloudstate.edu/cgi/viewcontent.cgi?article=1198\&context= engl_etds 
Bolgoa, N. (2019). Filipino English teachers in Japan: Non-native status and the teaching and learning of English. Journal of Language Teaching and Research, 10(2), 262. doi:10.17507/jltr.1002.06

Bryan, F. (2020). Is teaching English abroad the right move for me? Retrieved from https://www.budgetyourtrip.com/blog/2020/01/is-teaching-english-abroadthe-right-move-for-me/

Celik, B. (2017). The effects of working abroad on the development of teaching skills. International Journal of Social Sciences \& Educational Studies, 4(3), 214-215. doi:10.23918/ijsses.v4i3p212

Council on International Educational Exchange (CIEE). (2020). Discover the benefits of teaching abroad with CIEE. Retrieved from https://www.ciee.org/goabroad/work/teach-english-abroad

Ellwood, S. (2015). School board strengthening new international partnerships; EDUCATION: Sending teachers abroad to gain cultural experience. Observer's News. Retrieved from https://bit.ly/2WZMG2k.

Eusafzai, H. (2015). Foreign English language teachers' local pedagogy. English Language Teaching, 8(5), 90. doi:10.5539/elt.v8n5p82

Expat Quotes. (2020). Expat Teachers: Stories from Teaching Abroad: Guides for your expatriation - Expat-Quotes. Retrieved from https://www.expatquotes.com/guides/global/education/expat-teachers-stories-from-teachingabroad.htm

Explore Asia. (2020). Teach Abroad Programs. Retrieved from https://www.xploreasia.org/teaching-abroad-adventure-of-a-lifetime

Gul, H., \& Gokce, A. (2020). Challenges and Advantages of working abroad: Turkish and Turkish culture teachers' perspective. International Journal of Psycho-Educational Sciences, 9(1), 36. Retrieved from https:/ / files.eric.ed.gov/fulltext/EJ1250661.pdf

Johnson, G. (2013). Teaching English abroad. University Wire News. Retrieved from https:// bit.ly/3631Bgc

Kisch, M. (2013). Helping faculty teach international students. Georgia Tech. Retrieved from https://counselingcenter.ecu.edu/wp-content/pv uploads/sites/180/2020/05/TeachingInternationalStudents.pdf

Kong, P. (2020). Understanding the teachers' perspectives on the role of teacher autonomy in English classrooms in Chinese secondary schools. Journal of Educational Studies,3(2), 46-47. doi:10.1080/03055698.2020.1763784

Laverty, S. (2003). Hermeneutic phenomenology and phenomenology: A comparison of historical and methodological considerations. International Journal of Qualitative Methods, 2(3), 25-26. doi:10.1177/160940690300200303

Markoulias, K (2020) The experience of teaching abroad: pedagogical and other benefits (Master's thesis, Concordia University, Edmonton, Canada). Retrieved from https://spectrum.library.concordia.ca/979213/

Medved, D., Franco, A., Gao, X., \& Yang, F. (2013). Challenges in teaching international students: group separation, language barriers, and culture differences.Genombrottet, Lunds tekniska högskola.

Online English Teaching Jobs. (2020). The ultimate guide to teaching English abroad jobs. Retrieved from https://oetjobs.com/the-ultimate-guide-to-teaching-englishabroad-jobs/

Pachina, E. (2020, July 8). My journey as an English teacher abroad [Blog post]. Retrieved from https://www.teflcourse.net/blog/my-journey-as-an-english-teacherabroad-ittt-tefl-blog/ 
Serbes, M. (2017). Teaching abroad: Why teachers prefer teaching overseas. International Journal of Social Sciences \& Educational Studies, 4(3), 184. doi:10.23918/ijsses.v4i3p182

Serin, H. (2017). The effects of teaching abroad on personal and professional development. International Journal of Social Sciences \& Educational Studies, 4(1), 113-114. doi:10.23918/ijsses.v4i1p110

Toraman, C., Ozdemir, H. S., \& Orakci, S. (2020). Experiences of Turkish Teachers Working Abroad. Sage Journals, 5(2), 34-35. doi:10.1177/2158244020914655

Tosuncuoglu, I. (2017). Non-native and native English teachers. Journal of History Culture and Research, 6(6), 4. doi:10.7596/taksad.v6i6.573

Ulla, M. (2018). English language teaching in Thailand: Filipino teachers' experiences and perspectives. Issues in Educational Research, 28(4), 1090. Retrieved from https://www.researchgate.net/publication/328783554_English_language_teach ing_in_Thailand_Filipino_teachers'_experiences_and_perspectives

Ulla, M. (2019). Filipinos as EFL teachers in Bangkok, Thailand: Implications for Language Education Policy in the ASEAN Region. RELC Journal, 1(2), 12. doi:10.1177/0033688219879775

Walters, D. (2020). Teaching EFL: Why you should teach abroad. Retrieved from https:/ / www.saxoncourt.com/teaching-efl-why-you-should-teach-abroad/

Zayed, N. (2018) Teaching in Abroad: A Cross-Cultural Experience. Journal of Tourism and Hospitality, 7(4), 371. doi:10.4172/2167-0269.1000371

\section{Appendix 1 \\ Interview Schedule Guide Questions}

1. How would you generally describe your experience as an English teacher handling courses in non-English speaking countries? Please provide specific examples.

2. What brought you to teaching abroad and working with English as a Second Language (ESL) program?

3. What supports need to be in place for you to be successful English as a Second Language (ESL) teacher?

4. What experiences as an ESL teacher do you have and how these affect your teaching?

5. How did your experience change your perspective as regards to:
a. educational system;
b. teaching methods and techniques;
c. language programs and policies;
d. kinds of students; and
e. economic status? 